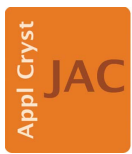

JOURNAL OF

APPLIED

CRYSTALLOGRAPHY

ISSN 1600-5767

Received 6 October 2014

Accepted 19 April 2015

Edited by K. A. Kantardjieff, California State University San Marcos, USA

Keywords: crystallization; crystallography; exhibitions; education; outreach.

Supporting information: this article has supporting information at journals.iucr.org/j

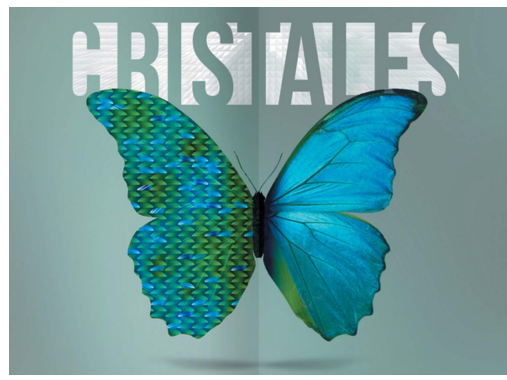

C 2015 International Union of Crystallography

\section{CRISTALES: a world to discover. An exhibition for schools and universities}

\author{
Juan Manuel Garcia-Ruiz,* Fermin Otalora, Alfonso Garcia-Caballero, Luis A. \\ González-Ramírez and Cristobal Verdugo-Escamilla
}

\author{
Laboratorio de Estudios Cristalográficos, Instituto Andaluz de Ciencias de la Tierra (CSIC-UGR), Avenida de las Palmeras \\ 4, Armilla, Granada 18100, Spain. *Correspondence e-mail: juanmanuel.garcia@csic.es
}

The exhibition CRISTALES: a world to discover is a teaching/outreach activity whose main goals are to increase awareness of the importance of crystallography and its role in everyday life in modern society, motivate young people, and promote education and research in crystallography. CRISTALES is designed to inspire the audience with a careful design and a view of crystallography that places the emphasis not only on the most important contributions of crystallography to society's welfare, including new materials and biomedical research, but also on those aspects of crystallography related to art and the mind. This article describes the simplest version of the exhibition, composed of 14 posters that have been created specifically for schools and universities. Each poster displays an image that is both aesthetically powerful and scientifically intriguing, so as to provoke the curiosity of the students. The posters also contain a brief text explaining the image and its relation to crystallography and a QR code that links the poster to a web page containing further information.

\section{Introduction}

Educational and outreach activities in crystallography and crystallization are of paramount importance not only for their relevance to several fields of research and technology but also because they enable the development of transferable skills such as spatial perception and the practical resolution of complex problems. Paradoxically, instruction in crystallography is almost absent in the formal syllabuses of most countries at primary and secondary educational levels, which leads to a lack of general knowledge among the public (Fanwick, 2007). On the one hand, this is a major obstacle when trying to explain crystallography: for example, many people wrongly believe that a glass is the same as a crystal and, at best, that crystals are just minerals, gems and precious stones. On the other hand, there is an interesting opportunity to use this lack of knowledge of crystallography to our advantage and take the visitor by surprise by showing something totally new. That was the main idea behind the video spot Crystallography: discover what crystallography can do for you (http://www.iycr2014.org/about/video) and this is, in turn, the basis behind the exhibition: The visitors will be confronted with images that they would never have thought of as crystallography related, thereby introducing a different world to which they were previously oblivious.

Different unconventional formats have been tried to support science teaching in schools, including multimedia applications with animated cartoons (Dalacosta et al., 2009), modelling structures (Cai et al., 2006), personal electronic response systems (Moss \& Crowley, 2011) and augmented reality applications (Sommerauer \& Müller, 2014). In parti- 
cular, science exhibitions are especially important not only in terms of cultural heritage but also as an informal teaching channel. The popularization of science based on the blending of education and entertainment had already become quite relevant during the Victorian era in England thanks to the important role of scientists who worked together with museums and exhibitions (Lightman, 2013). More recently, science exhibitions have been recognized as dynamic information spaces for knowledge building, highlighting the potential use of advanced technologies to support communication between the visitor, the exhibition and the museum (Knipfer et al., 2009).

A large variety of high-quality exhibitions were created for the International Year of Crystallography (IYCr2104; http:// www.iycr2014.org/events/exhibitions). Most exhibitions made a journey through history in order to explain the relevance of crystallography-related discoveries (Amorós, 1978). For example, Platonic solids and quasicrystals - moments in the history of crystallography (University of Uppsala, Sweden) and Reflections: tales from within the crystal (http://www. chemistry.unimelb.edu.au/news/crystallography-exhibitionopen-late-july) showed a collection of scientific books, models of crystals and instruments; In the unusual world of crystals (http://www2.chemia.uj.edu.pl/krysztaly_wystawa/) and Kristalle - Kunstwerke der Natur (http://www.aufhebenswert.at/ veranstaltungen/doppelausstellung-kristalle-kunstwerke-dernatur-trifft-keltische-kunst-heute) highlighed the beauty of crystals together with the history of their investigations and their various applications; Nobel structures: celebrating crystallography (http://nobelstructures.wix.com/home) aimed to raise awareness about the relevance that the main achievements of 29 Nobel Prizes have had; and Crystals: beauty, science, structure (http://blogs.mhs.ox.ac.uk/mhs/crystalsbeauty-science-structure/) looked at the history of crystallography from an artistic point of view. Many other exhibitions intended to disseminate the importance of crystallography from a general perspective. For instance, Cristalli! (http:// www.geoscienze.unipd.it/cristalli/welcome.html), The Big Bang Fair (http://www.thebigbangfair.co.uk/), Crystallography for humankind (http://xtal.dq.fct.unl.pt/iycr2014) and the exhibition Les 1001 facettes de la cristallographie of the University of Strasbourg (http://jardin-sciences.unistra.fr/annees-internationales/ cristallographie-2014/) basically explained theoretical and applied aspects of crystallography and their contribution to other scientific disciplines; Living with crystals (Slovenian Museum of Natural History; http://www.pms-lj.si/juliana/en/ 701) and Exhibición especial de cristales y estructuras (https:// sites.google.com/site/museotorresdelallosa/ano-internacionalde-la-cristalografia) showed crystallography from the mineral world. Interestingly, some exhibitions such as L'enigma Escher (http://www.palazzomagnani.it/2013/07/lenigma-escher) and Entre art et sciences: le corail en images, de l'animal au cristal (Centre Scientifique de Monaco; http://www.centrescientifique.mc/fr/) focused on the relationship between crystallography and art. Some exhibits preferred to focus specifically on conveying the significance of X-ray diffraction. In this category we find The two Braggs (http://www.amg122.com/twobraggs/), which reviewed the main achievements of William Laurence Bragg; Lattices and invisible rays (http://www.ub.lu.se/en/on-latticesand-invisible-rays), which focused on the discoveries of Röntgen, Laue and the Braggs; and Guided exhibition of crystals and $X$-ray diffraction equipment (http://www.coordinv. ciens.ucv.ve/jornadas/actividades/expcart.php), which paid attention to different X-ray equipment. There were other exhibitions that aimed to teach how to grow crystals and explain their applications. The Crystal nano-camp (http:// www.iycr2014.org/events/exhibitions/crystal-nano-camp) falls into this category. Finally, there is another type of exhibition, such as Crystallography in everyday life (http://www.science. org.au/crystallography-everyday-life-travelling-photo-exhibition), whose main aim was to illustrate the multiple applications of crystallography.

Whereas the majority of these exhibitions will be displayed in few locations, sometimes in only one museum, CRISTALES aims to reach the maximum number of young people throughout the world, having the following main objectives:

(1) To increase awareness of the importance of crystallography and its role in everyday life in modern society.

(2) To inspire young people and encourage citizen participation in the scientific process through activities associated with the exhibition or independently.

(3) To promote education and research in crystallography and its links with other scientific disciplines.

(4) To promote IYCr2104 and reflect on scientific knowledge and the role of science in our society.

The ultimate goal is for the posters to find a place in people's homes and, to this end, we have designed CRISTALES with three main criteria: attractive, modern and inexpensive.

\section{Conceptual basis of the exhibition}

The exhibition CRISTALES aims to convey a fresh insight into crystallography by placing an emphasis on the most appealing aspects and the most important contributions of crystallography to society, including new materials, solar energy, drug research, electronic materials, cosmetics and the design of new chemicals to improve industrial processes in various fields (http://www.iycr2014.org/_data/assets/pdf_file/ 0019/85303/Video-notes.pdf; http://www.iycr2014.org/_data/ assets/pdf_file/0010/78544/220914E.pdf). By doing this, the public is informed directly about the applications of crystallography in everyday life through simple and accessible language, thereby avoiding any technical details that may communicate crystallography as something complex and unfriendly.

CRISTALES has been specifically developed for schools and universities and is part of a larger exhibition created for the wider public. It is composed of 14 posters with the following main features:

(1) Each poster is, in essence, an aesthetically powerful image conveying a powerful scientific message. Each image has been designed to surprise the visitors, to make them wonder what they are looking at, i.e. why crystals are related to that attractive and intriguing image in front of them. 
(2) The posters send hidden messages of symmetry, texture, real and virtual space, intellectuality etc. The symmetry concept is given by the Spanish word for crystals 'CRIS$T A L E S$ ', in which the $\mathrm{T}$ is a letter with a mirror plane located in the centre of the word. The symmetry is further highlighted by the images, which are based on bilateral symmetry so that the right-hand side refers to the real world whilst the left-hand side is a texture inspired by some structural, physical or chemical property of crystals related to the image. This bilateral symmetry is further enhanced in such a way that the poster looks like the two pages of an open book. There is, however, one exception. In the poster related to biomineralization, the bilateral symmetry is deliberately broken in order to suggest the difference between the symmetry of life and that of the crystals.

(3) Below each image, there is some text that succinctly describes how the image is related to crystallography. The text ends with a couple of questions whose aim is to trigger the desire to learn more.

(4) Finally, below the text, there is a QR code that directs the visitor to a web page containing extended information about the posters and illustrative examples of spectacular applications of crystallography. The web page is not intended to be a comprehensive collection of information, but only a starting point to raise interest and promote the search for deeper knowledge. Instead, the web page works as an educational tool whereby teachers have access to information different from students, serving as a teaching guide. The QR code links the student to a page that tells them that this is a 'proactive' exhibition and that the answers to the questions suggested in the poster can be found in books.

(5) The posters will be available for download at a resolution high enough for high-quality printing.

(6) The ultimate goal is that teachers and students take home some of the posters, thus introducing the word 'crystals' into people's homes. This would be a good step forward towards popularizing crystallography.

\section{The 14 posters of the exhibition}

Each poster in the exhibition conveys an independent message on the important role of crystallography in our life and our world, but these topics are grouped into five thematic categories that highlight the importance of crystallography in different aspects of life:

(1) Crystals in our body and for our health

(2) Crystals in our environment

(3) Properties of crystals

(4) Crystals and technology

(5) Crystals in our mind

\subsection{Crystals in our body and for our health}

There are four posters that illustrate $(a)$ the role that crystals play in our body, $(b)$ the importance of crystallization in the final quality of the food that we eat, $(c)$ the fundamental information that crystallography provides in understanding how our body works, and $(d)$ the importance of crystals and structural crystallography in the design of drugs.

The concept of crystals in our body is shown by one of the most iconic and archetypical representations of the human body: the Vitruvian man (Fig. 1). The left-hand side of the picture is a texture inspired by calcium phosphate crystals, which account for about $50 \%$ of our bones. Thus, the first shocking message of the exhibition is that we as humans are standing upright because of crystals. In addition to bones, crystals also play a central role in the composition of our teeth and in the equilibrium system located in the inner ear. Their building chemicals and polycrystalline texture are the result of an astonishing evolutionary process that uses fascinating materials and processes. On the other hand, crystals in our body are also involved in the development of some illnesses, such as kidney stones, gallstones, osteoporosis or caries. Crystallography can help prevent or alleviate these processes,

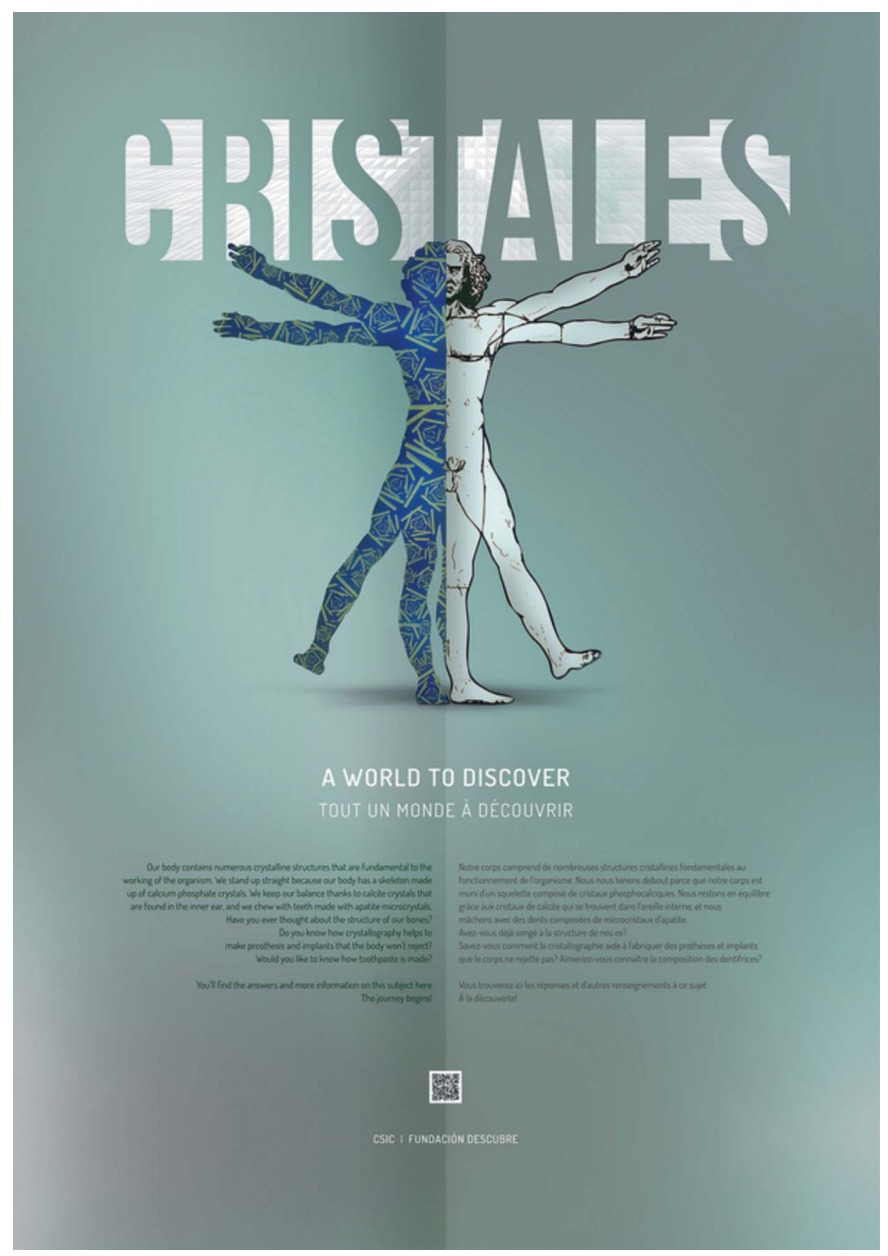

Figure 1

Our body contains numerous crystalline structures that are fundamental to the working of the organism. We stand up straight because our body has a skeleton made up of calcium phosphate crystals. We keep our balance thanks to calcite crystals that are found in the inner ear, and we chew with teeth made with apatite microcrystals. Have you ever thought about the structure of our bones? Do you know how crystallography helps to make prostheses and implants that the body won't reject? Would you like to know how toothpaste is made? 
for example by designing materials for prostheses and implants.

Crystals also play a crucial role in food technology. This concept is exemplified by an appealing ice cream (Fig. 2). On the left side of the picture beautiful dendritic snowflakes remind the visitor of the connection between food and crystallography: in this case, ice crystals. Edible crystals certainly include table salt and sugar, but not everybody is aware that crystallization plays an important role in the production of other types of food such as chocolate, butter and ice cream. The quality of these products, their safe production and distribution, and their taste and texture largely depend on the growth of the crystals they contain. Cocoa butter crystallizes in six different polymorphic forms, each of them possessing distinct physical properties. Among these properties is the melting point, which controls whether the chocolate melts on your tongue or in your hand, and its sticking properties, which

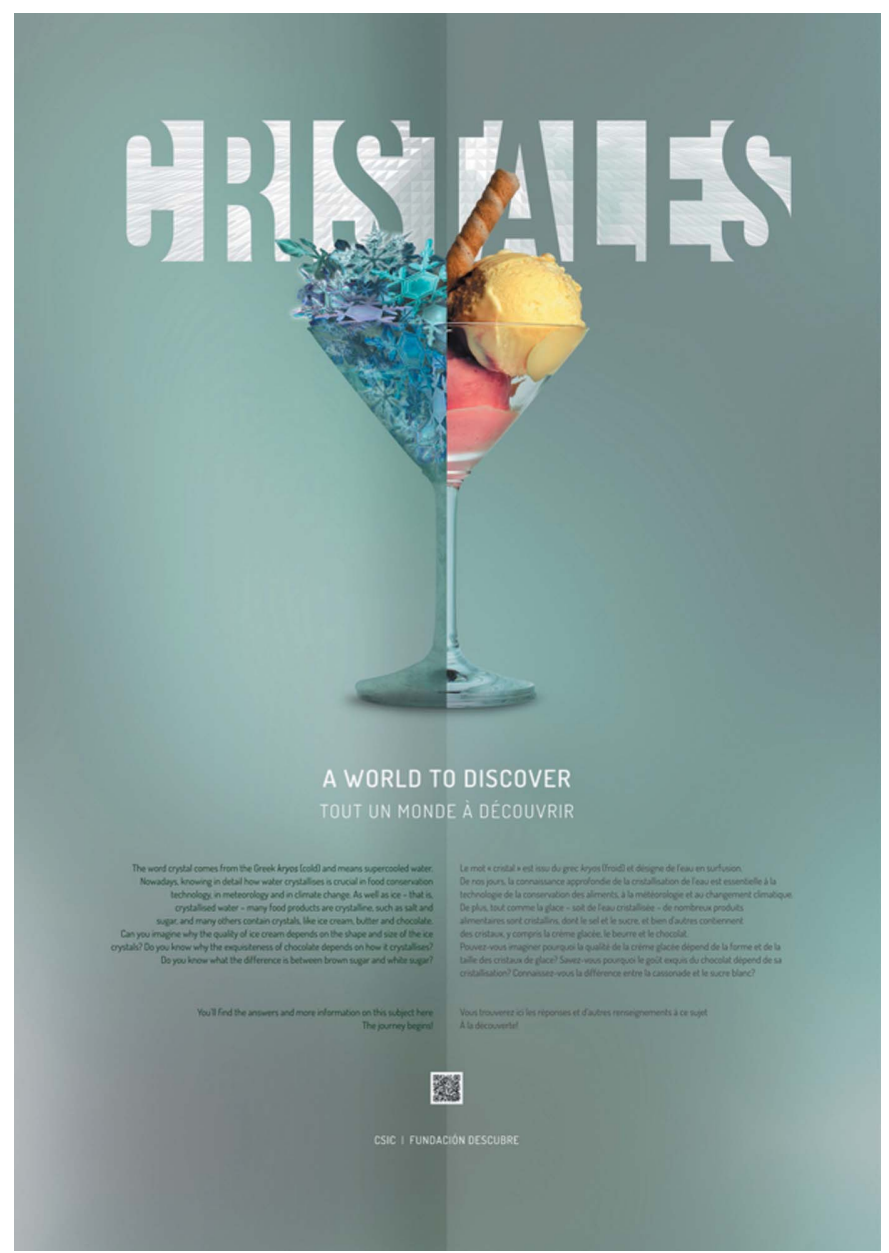

Figure 2

The word crystal comes from the Greek kryos (cold) and means supercooled water. Nowadays, knowing in detail how water crystallizes is crucial in food conservation technology, in meteorology and in climate change. As well as ice - that is, crystallized water - many food products are crystalline, such as salt and sugar, and many others contain crystals, like ice cream, butter and chocolate. Can you imagine why the quality of ice cream depends on the shape and size of the ice crystals? Do you know why the exquisiteness of chocolate depends on how it crystallizes? Do you know what the difference is between brown sugar and white sugar? determine if chocolate blocks can be easily extracted from the moulds during manufacture. The taste, texture and visual aspect of chocolate, which collectively define our experience when eating it, are also different. All in all, only the polymorph called 'form V' is the most suitable for commercial chocolates, and crystallographers are hired by industry to produce this form and avoid any phase change during distribution.

Frozen products are a major part of our diet because freezing is a safe way of storing foods. The ice crystals forming within food products during the freezing process must have the right size and shape distribution in order to avoid deterioration of the food and preserve its quality. In this case, crystallographic knowledge and technology help in providing healthy and tasty foods.

This poster may also be used by teachers to explain the differences between crystal and glass, the two main elements

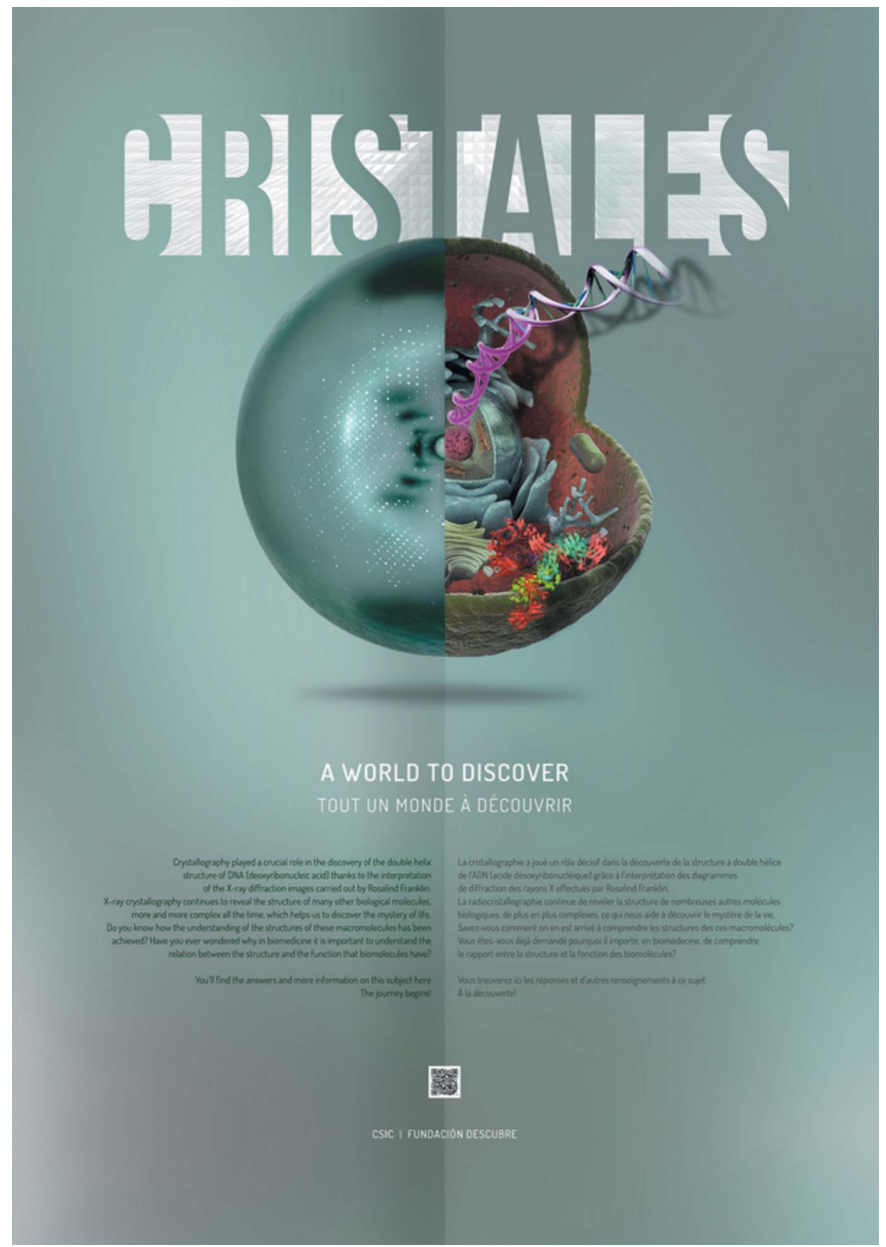

Figure 3

Crystallography played a crucial role in the discovery of the double helix structure of DNA (deoxyribonucleic acid) thanks to the interpretation of the X-ray diffraction images carried out by Rosalind Franklin. X-ray crystallography continues to reveal the structure of many other biological molecules, more and more complex all the time, which helps us to discover the mystery of life. Do you know how the understanding of the structures of these macromolecules has been achieved? Have you ever wondered why in biomedicine it is important to understand the relation between the structure and the function that biomolecules have? 
illustrated, or the etymological origin of the word 'crystal' from the Greek $\kappa \rho \nu \sigma \tau \alpha \lambda \lambda o \varsigma$ (ice, frozen water).

The relationship between crystallography and biology and medicine escapes most people. Therefore, the following poster (Fig. 3) deals with this subject by showing an animal cell, the cellular organelles inside, and the molecules (and proteins) that drive the reproduction and the functioning of cells. The left side of the picture displays the diffraction pattern of DNA collected by Rosalind Franklin and a diffraction pattern from a protein crystal, thus demonstrating how this knowledge has been obtained at the atomic and molecular scale. The message is clear and direct; a large part of our biological knowledge at the basic molecular level comes from crystallographic work. The teacher may use this poster to encourage students to study the story behind the discovery of DNA structure and to comprehend the role that biological macromolecules play in living organisms, especially in the control of biochemical

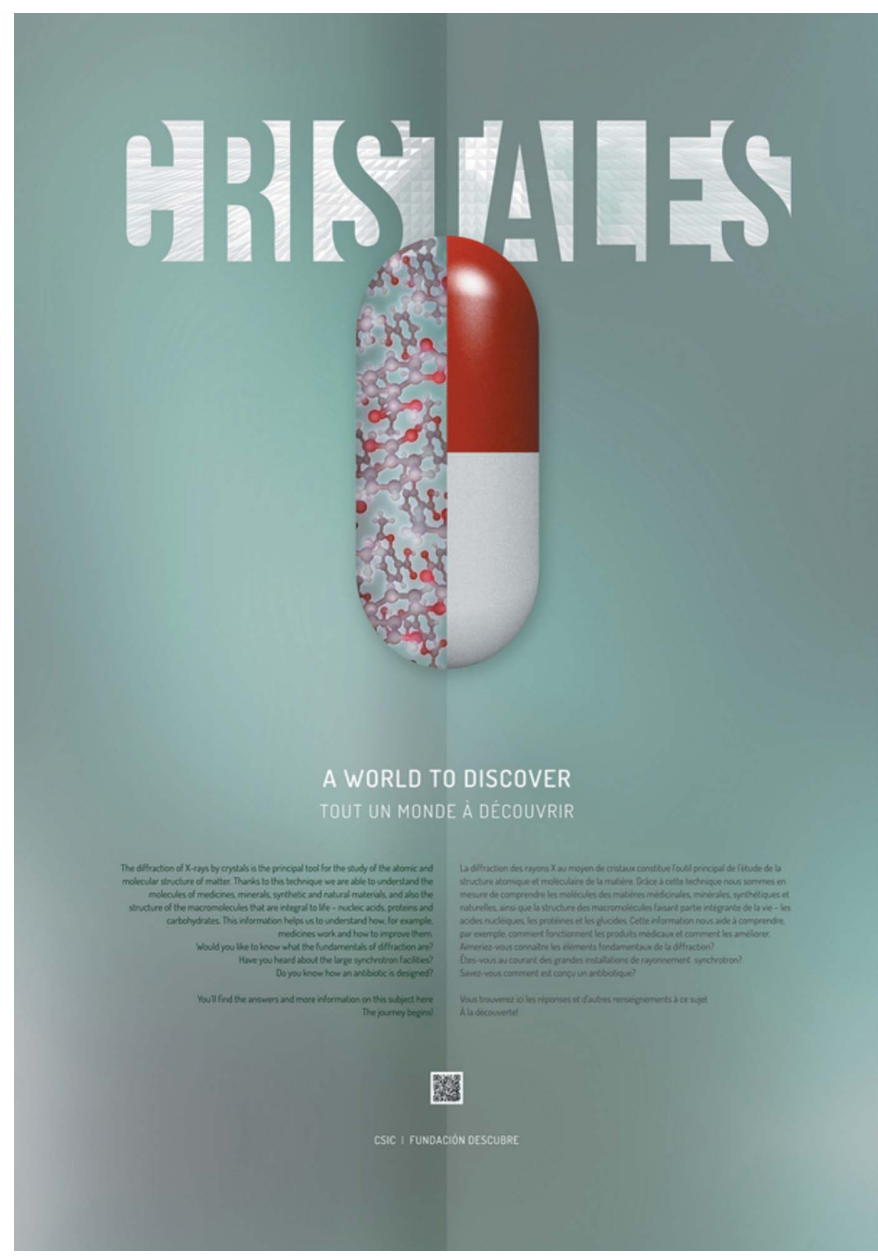

\section{Figure 4}

The diffraction of X-rays by crystals is the principal tool for the study of the atomic and molecular structure of matter. Thanks to this technique we are able to understand the molecules of medicines, minerals, and synthetic and natural materials, and also the structure of the macromolecules that are integral to life: nucleic acids, proteins and carbohydrates. This information helps us to understand how, for example, medicines work and how to improve them. Would you like to know what the fundamentals of diffraction are? Have you heard about the large synchrotron facilities? Do you know how an antibiotic is designed? processes (proteins) and genetic transmission of information (nucleic acids). They will find that crystals and crystallography are key to understanding life at the molecular level.

In fact, macromolecular crystallography makes a key contribution to our current understanding of how proteins work and how this information can be used to target specific diseases, improve biological processes and use enzymes for biotechnological processes. New therapeutic strategies based on knowledge about the structure and functions of proteins are being developed to target the active site of proteins and/or modify biochemical processes. This well established approach relies heavily on crystallographic knowledge. The role of crystallography in pharmaceutical science as a tool to study the molecular structure is presented in the next poster (Fig. 4),

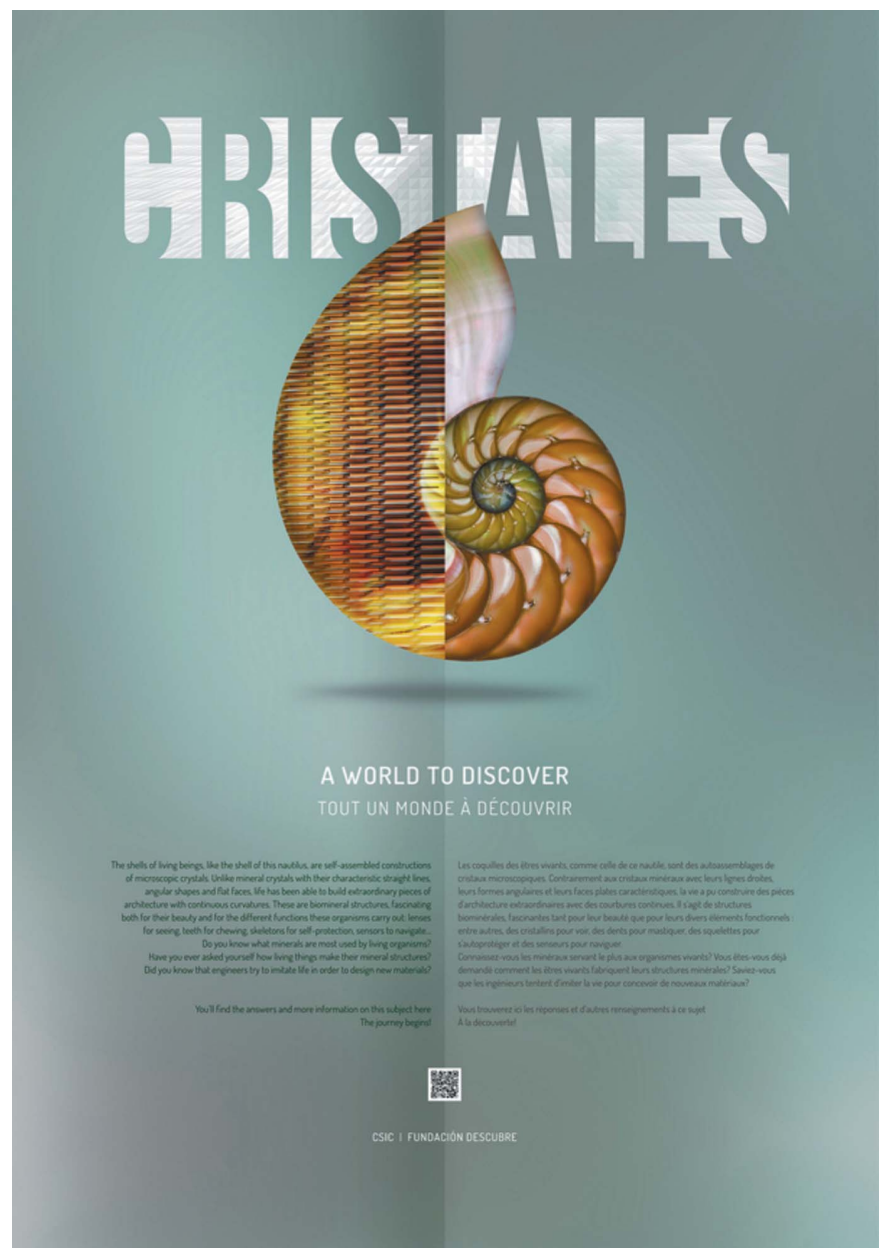

Figure 5

The shells of living beings, like the shell of this nautilus, are selfassembled constructions of microscopic crystals. Unlike mineral crystals with their characteristic straight lines, angular shapes and flat faces, life has been able to build extraordinary pieces of architecture with continuous curvatures. These are biomineral structures, fascinating both for their beauty and for the different functions these organisms carry out: lenses for seeing, teeth for chewing, skeletons for self-protection, sensors to navigate... Do you know what minerals are most used by living organisms? Have you ever asked yourself how living things make their mineral structures? Did you know that engineers try to imitate life in order to design new materials? 
which depicts a pharmaceutical capsule immediately recognizable by everybody.

\subsection{Crystals in our environment}

Crystallography is ubiquitous in the environment, being involved in several biological and mineral processes, as illustrated by two posters: the nautilus shell and Earth.

The shell of the nautilus is made of calcium carbonate crystals with a precise stacking that gives it its mechanical properties as well as the nacre (mother-of-pearl) lustre. The texture on the left side of the picture (Fig. 5) is inspired by this packing of calcium carbonate crystalline platelets. Organisms use crystals as structural elements, but also in their teeth or even as sensors, like the rows of magnetite crystals that are used as a tiny compass by some bacteria or the calcium carbonate structure in the inner ear of vertebrates that sense gravity. The multifunctional properties of these materials are

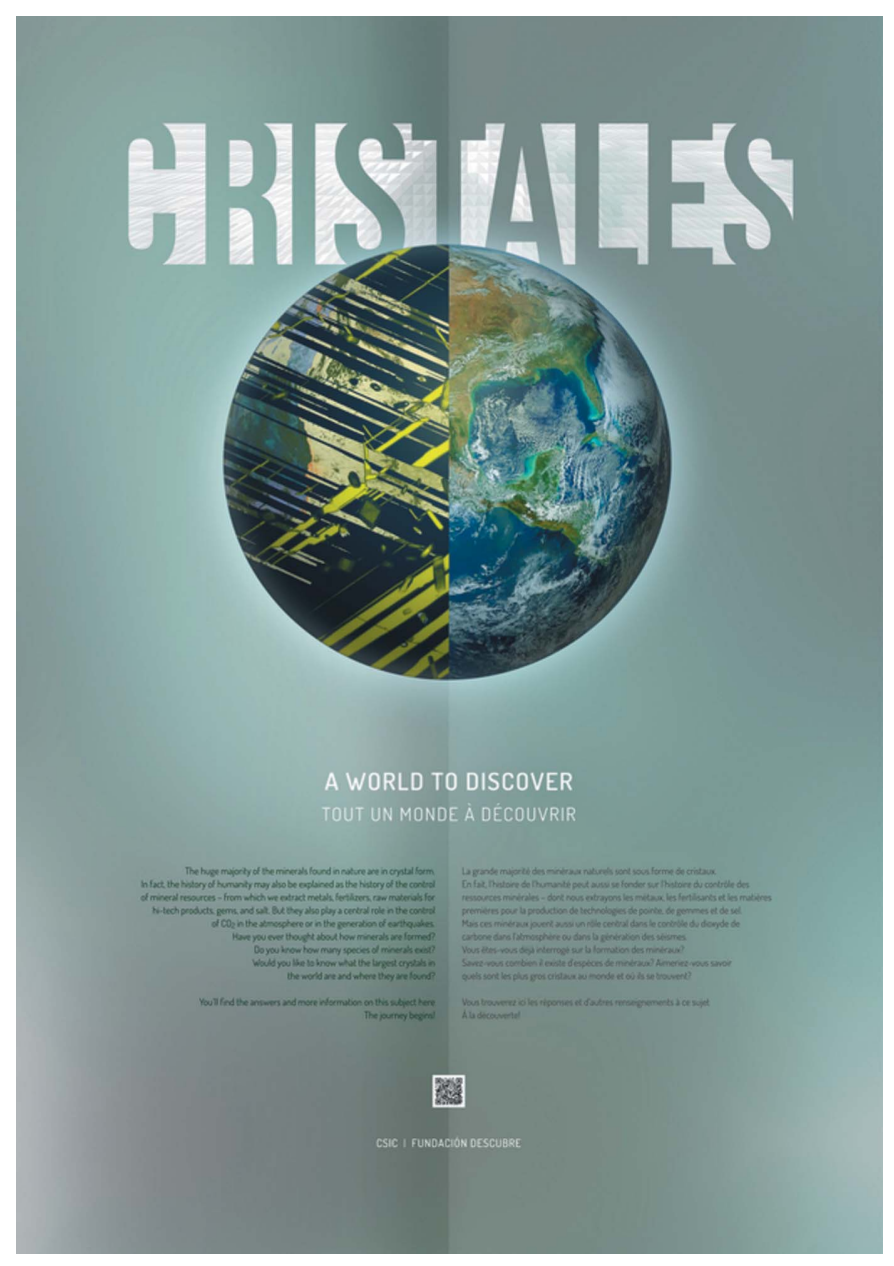

Figure 6

The huge majority of the minerals found in nature are in crystal form. In fact, the history of humanity may also be explained as the history of the control of mineral resources, from which we extract metals, fertilizers, raw materials for hi-tech products, gems and salt. But they also play a central role in the control of $\mathrm{CO}_{2}$ in the atmosphere or in the generation of earthquakes. Have you ever thought about how minerals are formed? Do you know how many species of minerals exist? Would you like to know what the largest crystals in the world are and where they are found? generally far superior to those engineered by man and, for this reason, biomineral structures are studied with the aim of producing equivalent materials for technological uses. This discipline is called biomimetics and it mainly relies on crystallographic knowledge.

The poster showing a nautilus shell is the only one in the exhibition that completely breaks the mirror symmetry of graphics. This has been done on purpose because the morphology of biominerals is usually controlled by the biology of the organism rather than by the crystallography of the compound. This duality is currently a hot topic in science.

Crystals are all around in our environment and almost every rock on the planet is made of crystals. To convey this message, the next poster (Fig. 6) shows planet Earth from space and a petrographic cut of a crystalline rock on the left side of the picture. Beyond the historical role of mineral crystals in the development of crystallography, this poster introduces other topics including the role of mineralization in the geochemistry of the Earth's crust, and its effect on the atmosphere and the climate. Modern studies on the crystallography of minerals allow us to understand the processes involved in the global dynamics of the planet, the generation of earthquakes, and the geochemical scenario for the origin of life and its early development. The crystallographic characteristics of minerals are due to the physical and chemical conditions in which they grew and can be used to decode this information, extremely important from the geological point of view. Obviously, this decoding process relies on deep crystallographic knowledge.

\subsection{Properties of crystals}

The main properties of crystals that define their nature and their importance in life and technology are addressed by a set of three posters. The first poster in the series (Fig. 7) introduces the topics of periodicity and symmetry, key to the concept of crystals. The poster shows a periodic two-dimensional ceramic tiling from the Reales Alcázares of Seville (Spain) on the right-hand side of the picture and the symmetry elements defining the relationship between the different tiles in the ceramic on the left side. This type of tiling is very common in the ornamentation of Muslim architecture from the Late Middle Ages and has been frequently used to illustrate symmetry concepts in crystallography because all the symmetry operations and groups are present and the patterns are very appealing. The selected pattern displays inversion centres, rotation axes, mirror planes and glide planes, making it well suited to introduce all these concepts. More than one unit cell is included in the pattern to also make it appropriate for the discussion of translational symmetry, the unit cell and the asymmetric unit.

Two other properties of crystals are fundamental in order to get a complete view of the role of crystals in our world: polymorphism and chirality. Polymorphism, the ability of a compound to crystallize in different crystal structures, is introduced by a poster showing a crystal on the right-hand side and the structure of graphite on the left (Fig. 8). This is a very illustrative example of polymorphism because the properties 
of diamond and graphite are very different and well known to the public. At the same time, the technological applications of carbon nanotubes, fullerenes and graphene allow for a more in-depth discussion about the relationship between structure and property. This poster can be used to introduce other major topics such as the importance of polymorphism for the chemical and pharmaceutical industry, crystal defects (like the origin of colour in diamonds), and how crystal quality and the presence of impurities or other crystal defects has a deep impact on the properties and value of crystals.

Although chirality, the ability of a given molecule or a given crystal to display either a left-handed or a right-handed configuration, is itself a molecular rather than crystallographic concept, its practical importance and relation to symmetry more than justifies devoting one of the posters to this concept. Furthermore, the methods of chiral separation by crystallization that are currently a hot topic in crystallization science

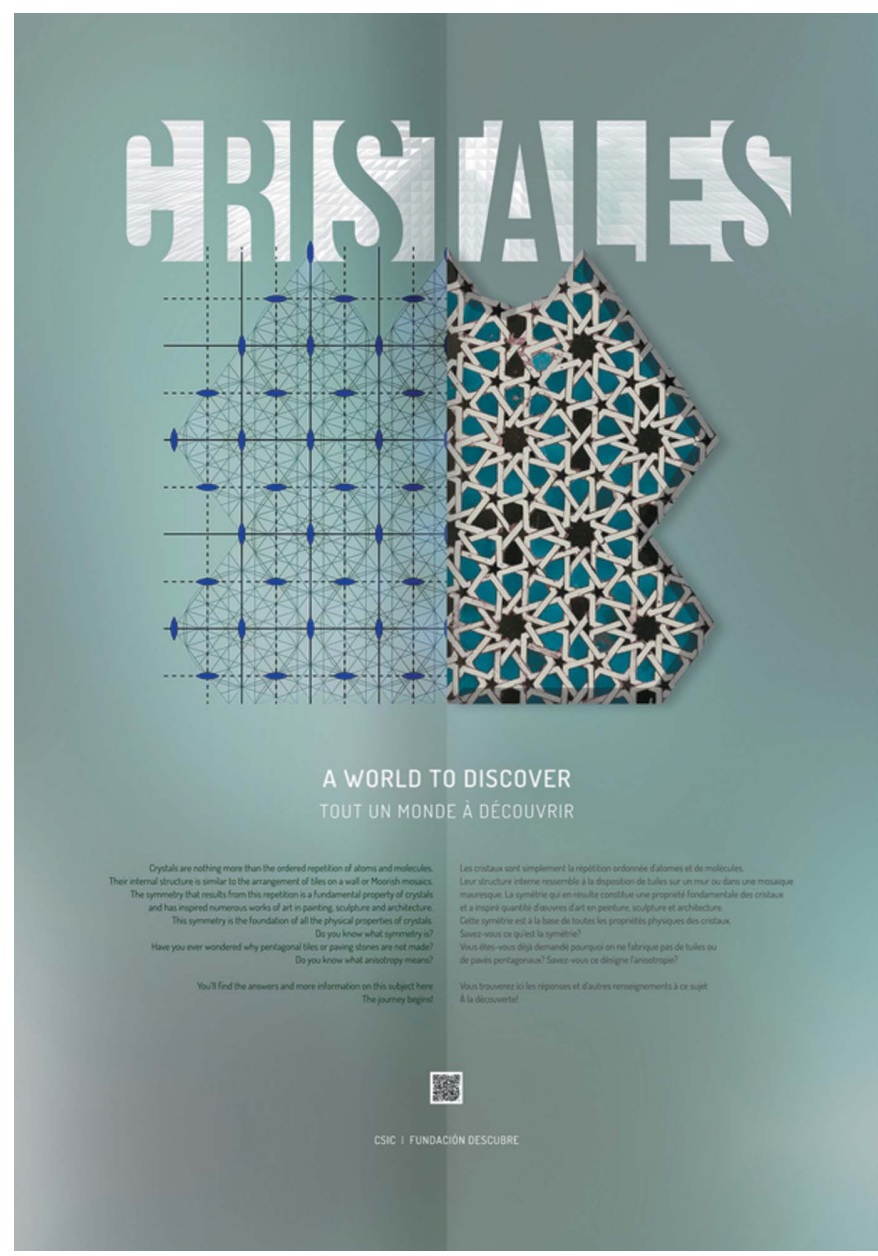

Figure 7

Crystals are nothing more than the ordered repetition of atoms and molecules. Their internal structure is similar to the arrangement of tiles on a wall or Moorish mosaics. The symmetry that results from this repetition is a fundamental property of crystals and has inspired numerous works of art in painting, sculpture and architecture. This symmetry is the foundation of all the physical properties of crystals. Do you know what symmetry is? Have you ever wondered why pentagonal tiles or paving stones are not made? Do you know what anisotropy means? make them an excellent subject for the exhibition. The poster shows a real hand as seen in everyday life and another hand with the structure of limonene, a nice example of chirality because one of the enantiomorphs produces the aroma of orange and the other of lemon. This fact is illustrated by the orange and yellow spheres (Fig. 9). Other possible examples of the effects of chirality on the chemical properties of compounds such as the case of thalidomide were disregarded in order to avoid drama and maintain the positive message of the exhibition. Other important topics introduced by the poster are the selective nature of life when producing proteins or nucleic acids. This concept is particularly well suited because macromolecular structure is also addressed by the

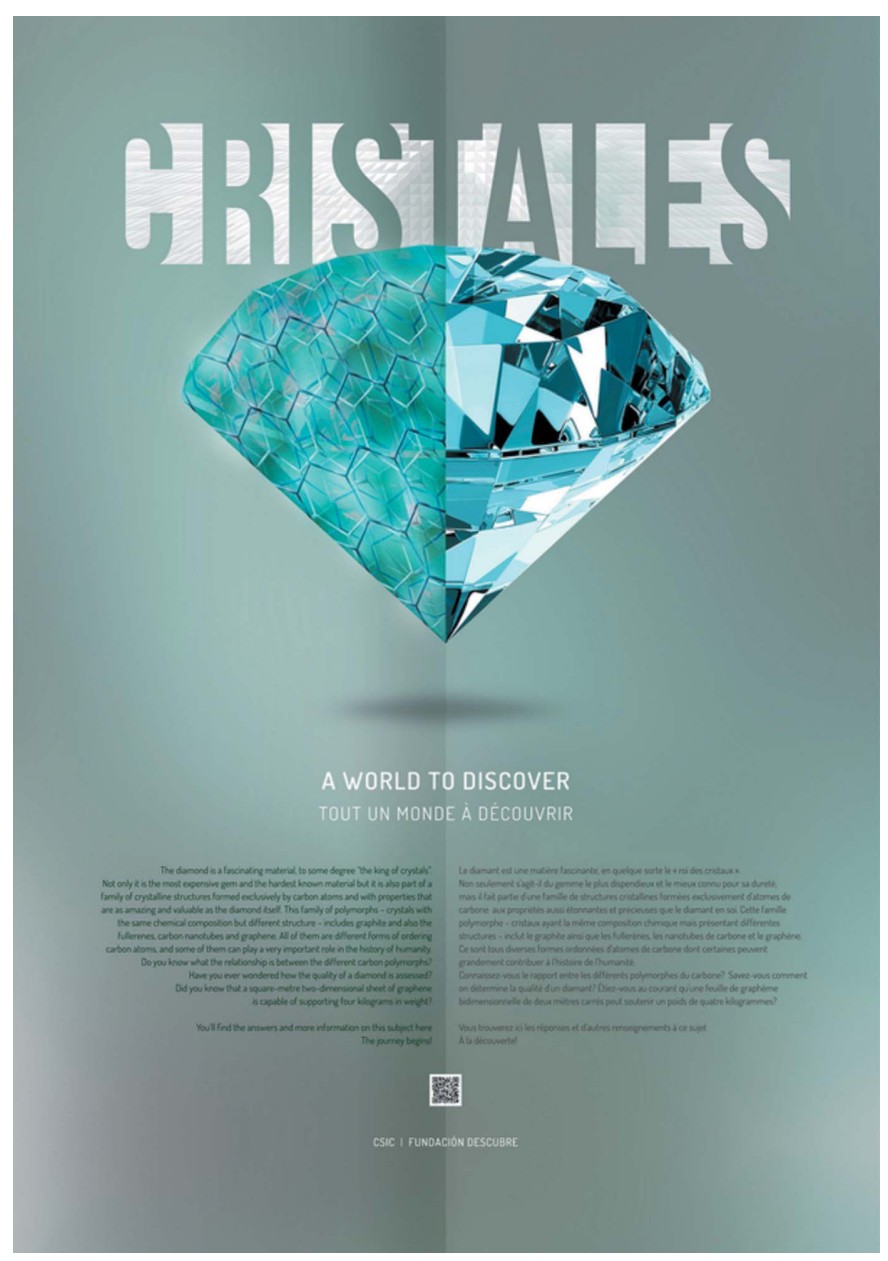

Figure 8

Diamond is a fascinating material, to some degree 'the king of crystals'. Not only is it the most expensive gem and the hardest known material but it is also part of a family of crystalline structures formed exclusively by carbon atoms and with properties that are as amazing and valuable as the diamond itself. This family of polymorphs (crystals with the same chemical composition but different structure) includes graphite and also the fullerenes, carbon nanotubes and graphene. All of them are different forms of ordering carbon atoms, and some of them can play a very important role in the history of humanity. Do you know what the relationship is between the different carbon polymorphs? Have you ever wondered how the quality of a diamond is assessed? Did you know that a square-metre two-dimensional sheet of graphene is capable of supporting four kilograms in weight? 
exhibition, which establishes links between the pieces of knowledge acquired from different posters.

\subsection{Crystals and technology}

Technology provides an excellent opportunity to introduce the role of crystals in our daily life because of the general positive perception of technology and the widespread use of crystalline materials in different technological fields. Electronics is a very clear example of this. Virtually all aspects of our current world rely on the use of electronic devices that would not work without semiconductor crystals. The operation of silicon microcircuits depends on the electronic properties of crystalline semiconductors. Some features of the crystal lattice,

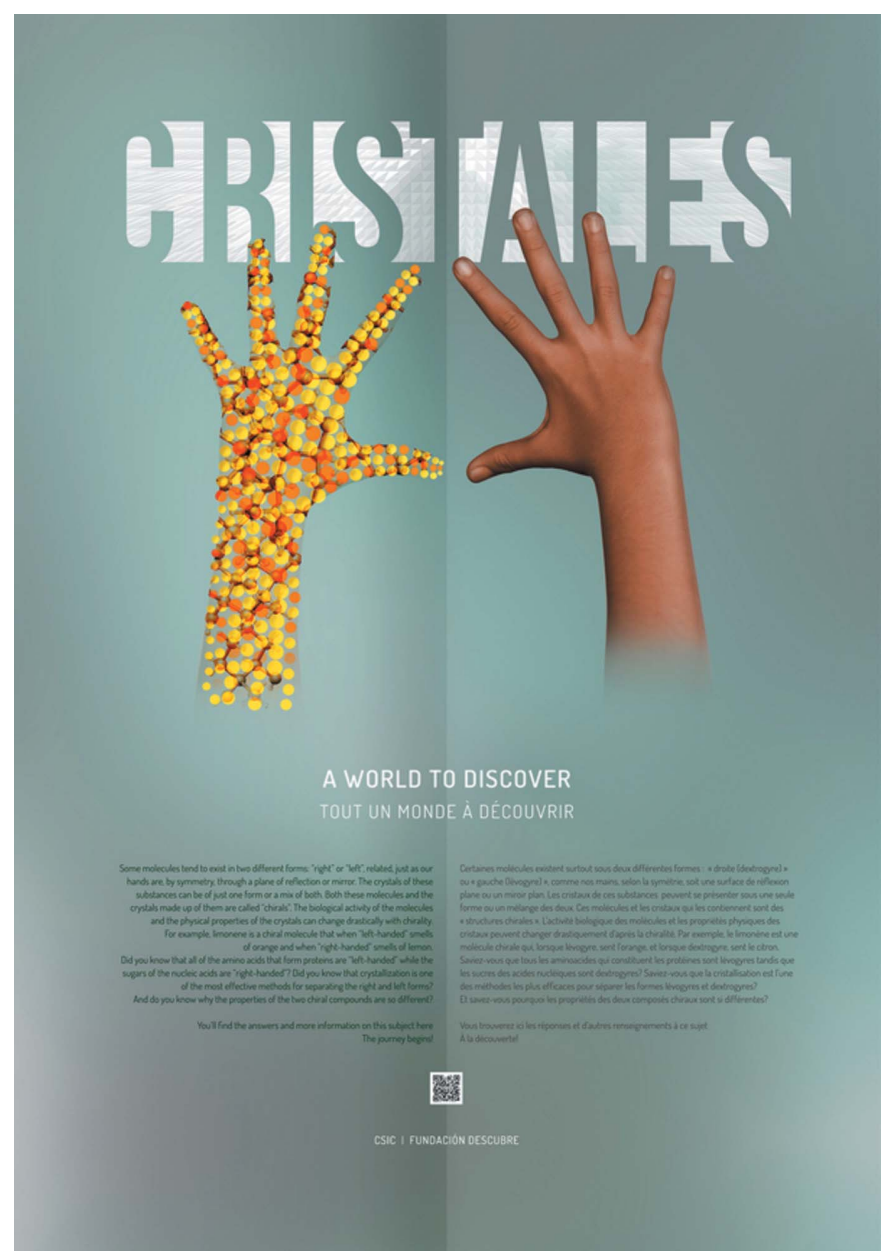

Figure 9

Some molecules tend to exist in two different forms: 'right' or 'left', related, just as our hands are, by symmetry, through a plane of reflection or mirror. The crystals of these substances can be of just one form or a mix of both. Both these molecules and the crystals made up of them are called 'chiral'. The biological activity of the molecules and the physical properties of the crystals can change drastically with chirality. For example, limonene is a chiral molecule that when 'left handed' smells of orange and when 'right handed' smells of lemon. Did you know that all of the amino acids that form proteins are 'left handed' while the sugars of the nucleic acids are 'right handed'? Did you know that crystallization is one of the most effective methods for separating the right and left forms? And do you know why the properties of the two chiral compounds are so different? such as the presence of defects, are extremely detrimental for their use, while others, like controlled distributions of impurities, are required to optimize and tune their properties.

However, it is not only semiconductors where crystals play a central role in technology. The construction of electronic watches that pace the operation of electronic circuits as well as a number of different transducers (the best known probably being microphones) is made both possible and very cheap by piezoelectricity. A large number of other transducers and actuators require or benefit from the physical properties of crystals, which allow electronics to interact with the real world. The poster in Fig. 10 illustrates this fact using an electric guitar, for the younger public. In general, older people are more aware of the operation principles of electronics because most of these technologies have emerged or developed during

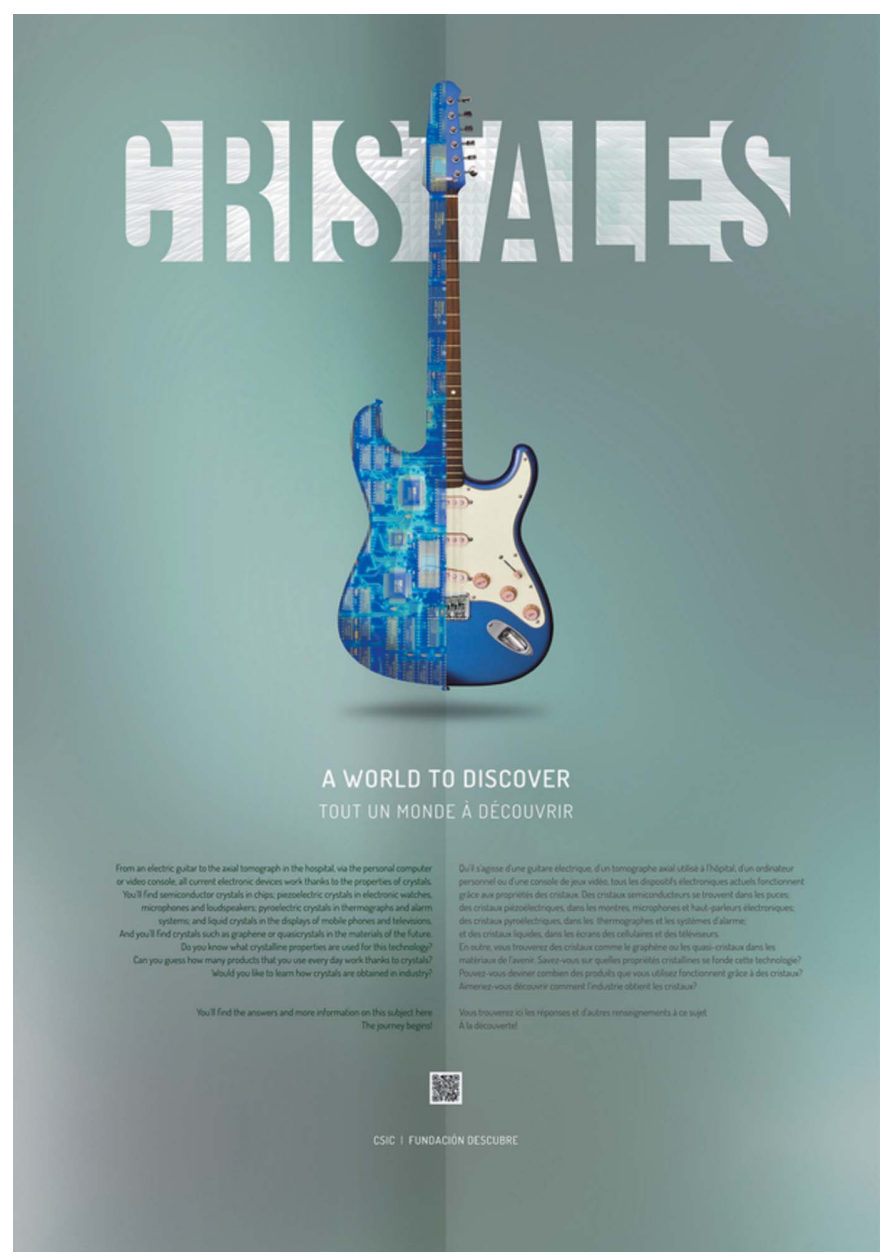

Figure 10

From an electric guitar to the axial tomograph or the ultrasound scanner in the hospital, via the personal computer or video console, all current electronic devices work thanks to the properties of crystals. You'll find semiconductor crystals in chips; piezoelectric crystals in electronic watches, microphones and loudspeakers; pyroelectric crystals in thermographs and alarm systems; and liquid crystals in the displays of mobile phones and televisions. And you'll find crystals such as graphene or quasicrystals in the materials of the future. Do you know what crystalline properties are used for this technology? Can you guess how many products that you use every day work thanks to crystals? Would you like to learn how crystals are obtained in industry? 
their lifetime, so it is more likely that they have been exposed to information on their operation at a popular level. The latest trends of continuous miniaturization and the increase in software complexity have shifted the focus to software, operating systems and applications, making younger people less aware about the crystals inside their appliances. Videogames were selected at first for this reason, but the rights to show game characters were denied by the two companies of the sector that we approached.

Beyond electronics, crystals play a central role in the fields of biomineralization, nanotechnology and biotechnology. Two posters of the exhibition are devoted to these topics. Biomineralization and biotechnology are introduced by an egg that, on the left-hand side, depicts the amazing design of the eggshell, evolved over millions of years to be the perfect container for biological materials because of its mechanical resistance and antibacterial properties (Fig. 11). The eggshells of birds are made of calcite crystals self-arranged by crystal

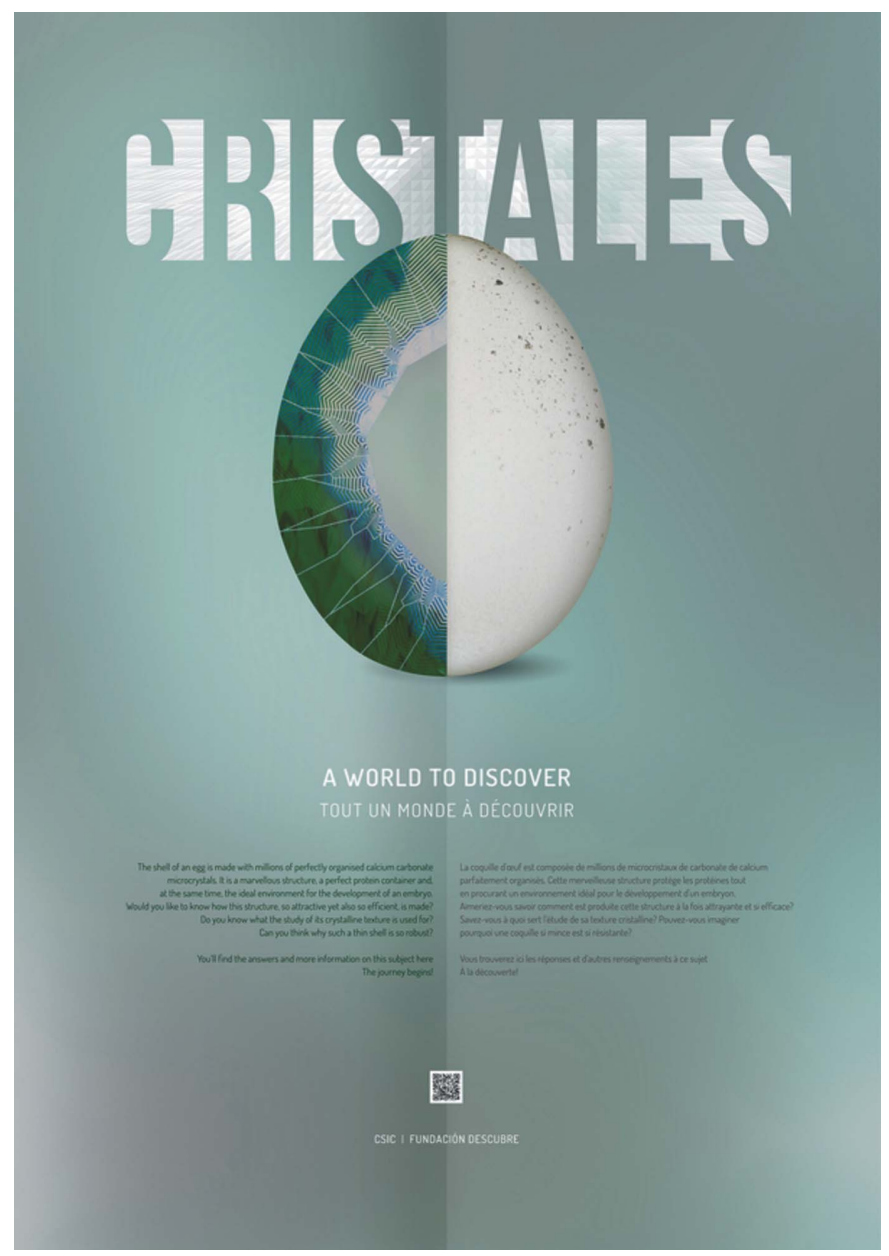

Figure 11

The shell of an egg is made with thousands of perfectly organized calcium carbonate microcrystals. It is a marvellous structure, a perfect protein container and, at the same time, the ideal environment for the development of an embryo. Would you like to know how this structure, so attractive yet also so efficient, is made? Do you know what the study of its crystalline texture is used for? Can you think why such a thin shell is so robust? growth. The crystallographic direction of the crystals and the overall texture of the polycrystals are crystallographically controlled. These highly efficient materials are currently inspiring and showing scientists and engineers new ways to tailor materials for specific technological applications.

The poster of the butterfly (Fig. 12) introduces the topic of photonic crystals and other nano- and microscale periodic arrangements that are crucial to technology because of the periodic arrangement of nanostructures. The fact that some of the deep colours of butterflies are due to the scattering and interference of light offers an excellent opportunity to explain the basic concepts behind diffraction and the technological implications of this fundamental process. With this type of crystal made of non-molecular units it was decided to convey the idea that crystallography is not restricted to studying molecules. The huge success of structural crystallography

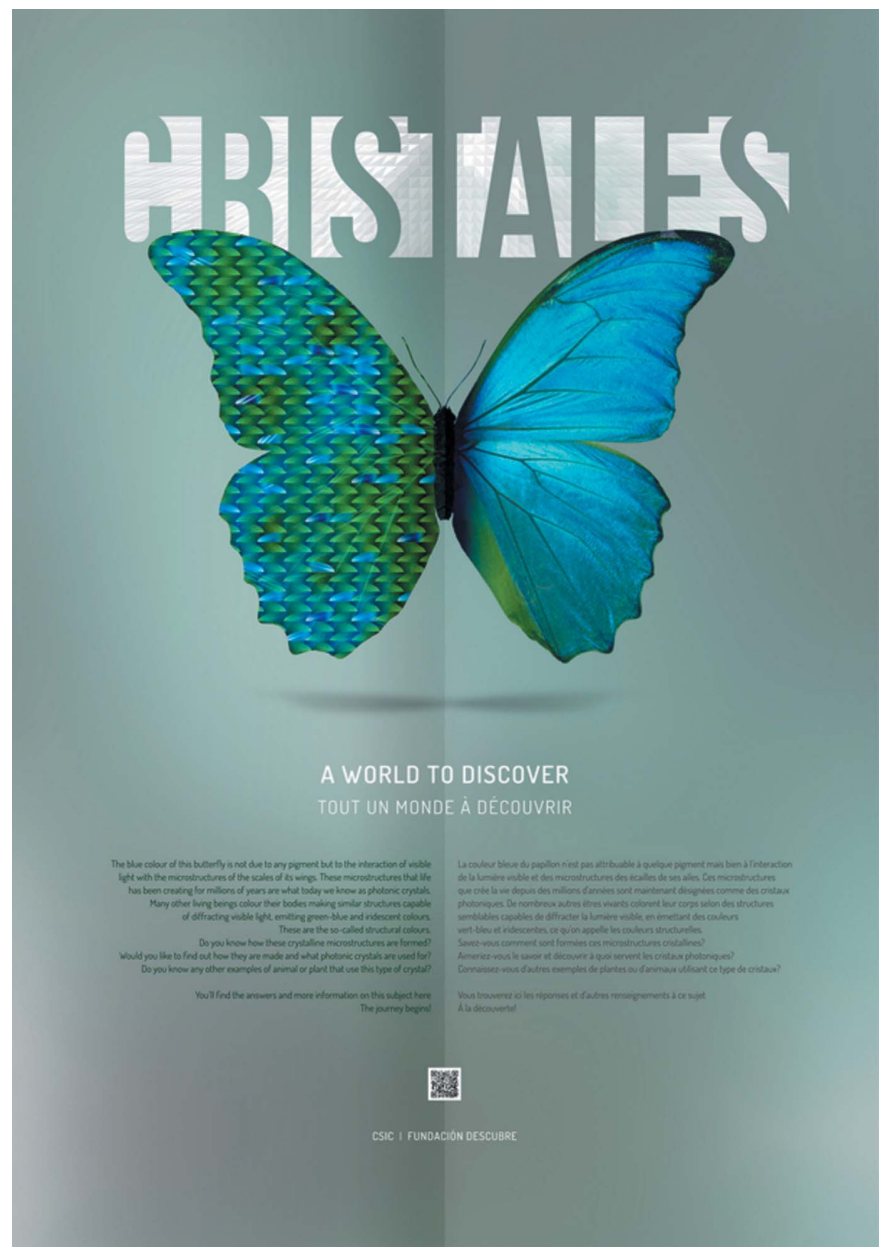

Figure 12

The blue colour of this butterfly is not due to any pigment but to the interaction of visible light with the microstructures of the scales of its wings. These microstructures that life has been creating for millions of years are what today we know as photonic crystals. Many other living beings colour their bodies making similar structures capable of diffracting visible light, emitting green-blue and iridescent colours. These are the socalled structural colours. Do you know how these crystalline microstructures are formed? Would you like to find out how they are made and what photonic crystals are used for? Do you know any other examples of animal or plant that use this type of crystal? 
during the past century has somehow overshadowed crystallography as an independent scientific field. In this exhibition a great effort is made to highlight the fact that crystallography is not a branch of chemistry but an independent field contributing with knowledge, expertise and methods to chemistry and to a number of other disciplines.

The last poster in this group (Fig. 13) is devoted to crystals for energy technologies. The poster shows a gasoline pump and, seen through crystallography, a typical zeolite crystal structure. Different types of crystals are used in the energy industry because of their physical properties. Notable examples include the one illustrated, zeolites, which are used in the efficient production of gasoline as well as for water purification, silicon for solar energy and materials for energy storage, and energetically efficient electronics. Crystalline materials are also used, typically because of their surface properties, in the remediation of the pollution caused by the production and use of energy. The continuous improvement of the properties

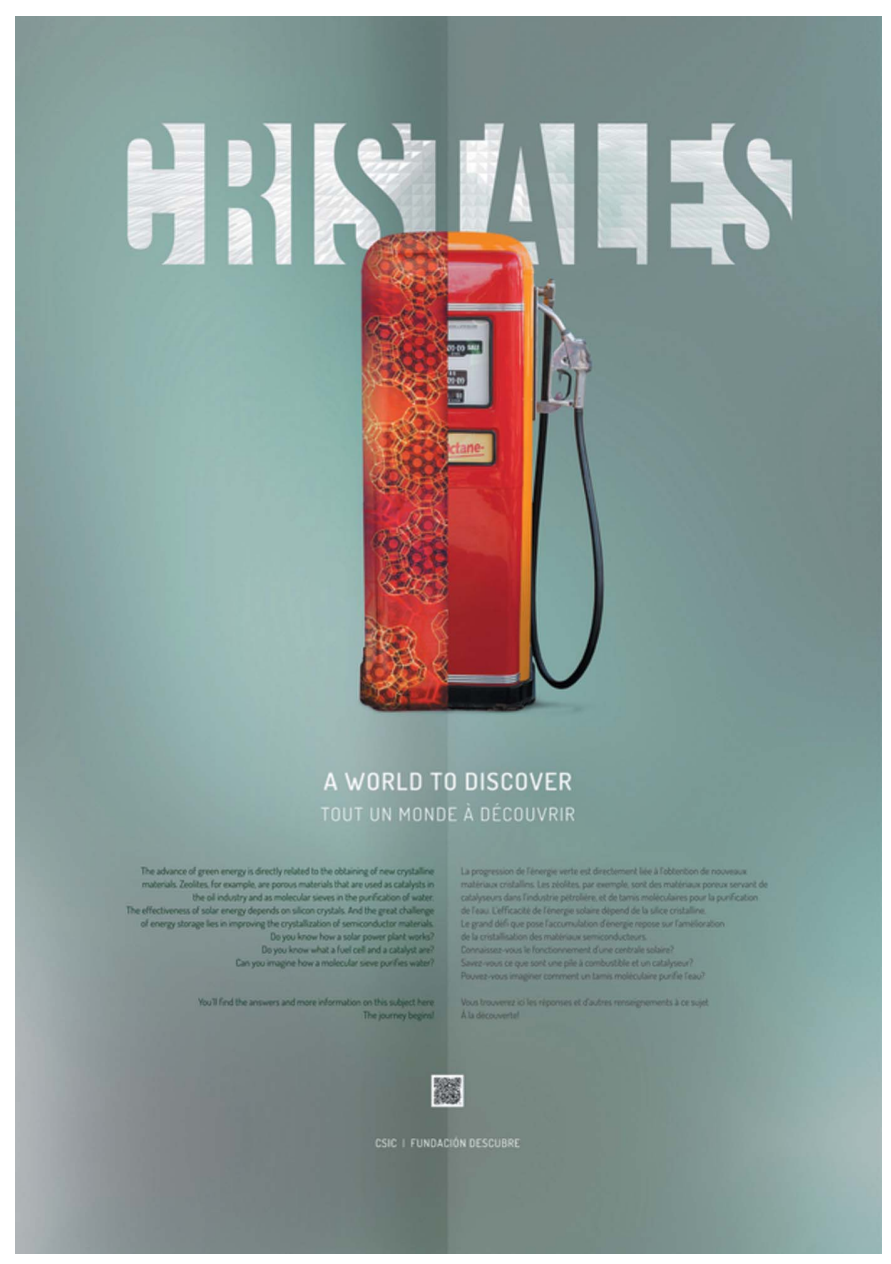

Figure 13

The advance of green energy is directly related to the obtaining of new crystalline materials. Zeolites, for example, are porous materials that are used as catalysers in the oil industry and as molecular sieves in the purification of water. The effectiveness of solar energy depends on silicon crystals. And the great challenge of energy storage lies in improving the crystallization of semiconductor materials. Do you know how a solar power plant works? Do you know what a fuel cell and a catalyst are? Can you imagine how a molecular sieve purifies water? of crystalline materials for the energy industry ensures a more efficient and responsible use of resources.

\subsection{Crystals and our mind}

The last poster of the exhibition (Fig. 14) deals with a subject that does not appear in most exhibitions on crystals/ crystallography but that we consider of enormous interest for the general public and therefore very important for increasing society's awareness of crystallography. It deals not with technology but with the mind and culture. It has been shown that human fascination for crystals is so deeply rooted in our brains as to shape our perception of straightness and order, such as the geometric arrangements of objects (García-Ruiz, 2015). This fascination provoked by external order increased following the development of the theory of crystals as made of ordered repetition of small units of matter, the molécules intégrantes, that pile to fill the entire volume (Haüy, 1784). It

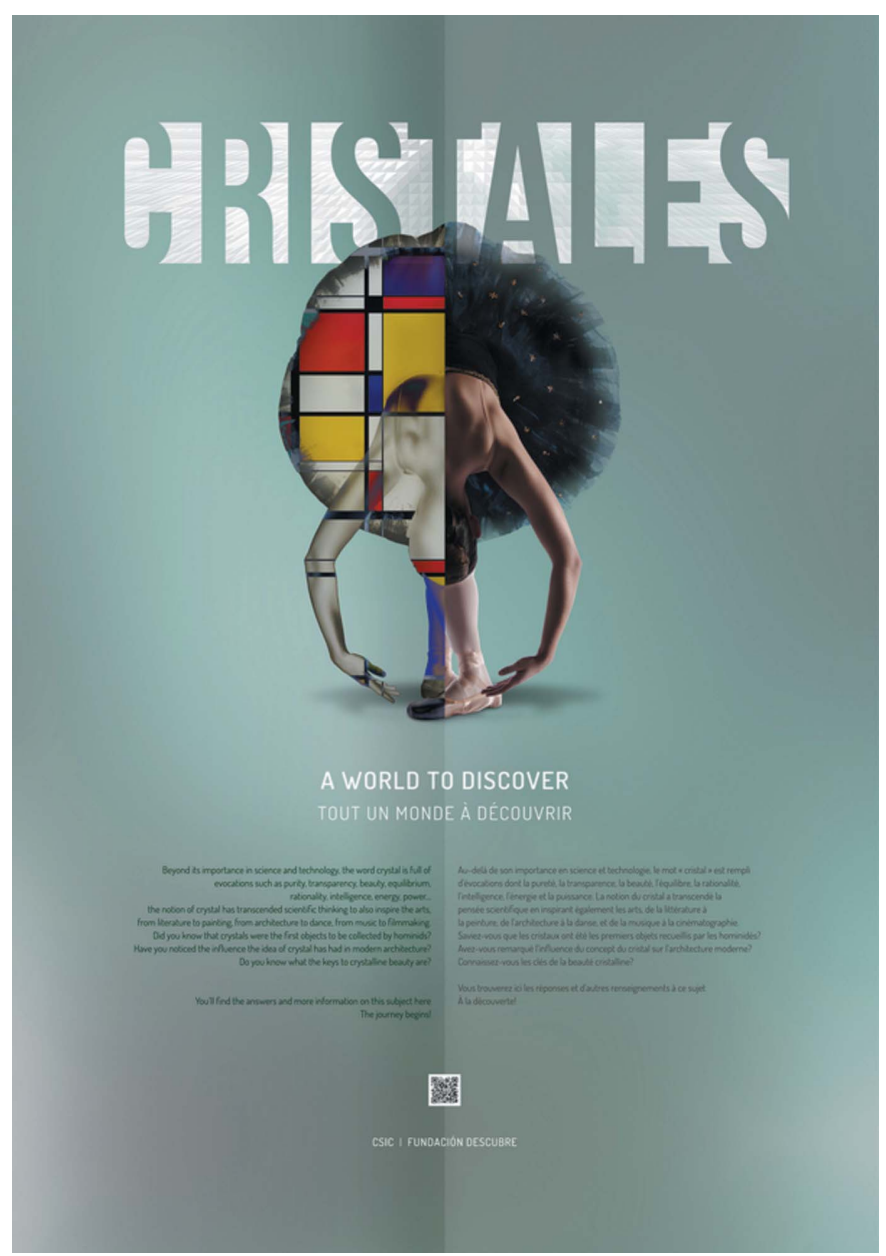

Figure 14

Beyond its importance in science and technology, the word crystal is full of evocations such as purity, transparency, beauty, equilibrium, rationality, intelligence, energy, power... The notion of crystal has transcended scientific thinking to also inspire the arts, from literature to painting, from architecture to dance, from music to filmmaking. Did you know that crystals were the first objects to be collected by hominids? Have you noticed the influence the idea of crystal has had in modern architecture? Do you know what the keys to crystalline beauty are? 
was shown how the beauty of the external order, the morphology, derives from the ordered arrangement of the internal structure of crystalline matter. Since then, after the transposition of this idea from academic science to popular culture, crystals have evoked not only fascination and mystique, as they had before, but also concepts such as purity, transparency, beauty, equilibrium, rationality, power etc. Thus, the new idea of the crystal as ordered matter developed during the nineteenth century has permeated culture beyond science to impact all arts and natural philosophy. Although the neurological mechanisms by which crystals have configured the intellectual structure of the brain and its evolution throughout history are currently unknown and will probably remain speculative, it is without doubt that the idea of the crystal has influenced art in all its forms.

Out of all the art forms we could have chosen for this poster, that of dance is probably the most unexpected that the spectator would relate with crystals. However, it can be demonstrated that the work of several choreographers, especially Laban, has explicitly shown how crystallography has influenced not only the style but also the language of dancing (Dörr, 2008). The poster shows a dancer bowing to display her black tutu perpendicular to the glance of the visitor. The right half is the real image of the tutu, while the left part features a purist style painting characteristic of crystal-inspired art. For the left 'textured' part of the image we considered using the paintings Mademoiselles de Avignon by Picasso or Galatea of the spheres or Dali naked in ecstasy before five regular bodies, which are academically more relevant to the subject addressed in this poster, but we were unable to buy the right to use copies of these pictures. The final version uses a Mondrian-like view that is also beautiful, relevant and appealing.

\section{Web site}

We have created a web site, http://cristales2014.org, devoted to the CRISTALES exhibition. On this web site there are 14 web pages corresponding to each of the posters of the exhibition described above. The QR codes of the posters link the visitors and students to the corresponding web pages, where they will find additional information and links to other pages related to the specific topic of the poster. Moreover, the web site http:// cristales2014.org contains additional information that teachers and students can use. As described above, this exhibition is part of a larger one including other posters and installations, namely the following:

(1) A set of 14 additional posters on the topics of the exhibition but closer to conventional exhibition posters, i.e. including longer texts and additional figures. These posters will be displayed in larger exhibitions by organizations that can afford transport costs and larger installations. Low-resolution versions of these additional posters are also available on the web site, along with explanatory texts (about two to four pages) on the subject of each of them.

(2) A set of six interactive installations also intended for larger institutional exhibitions has been developed for the exhibition. They introduce the following: (a) Crystal units, crystal packing and crystal growth can be explored with a few hundred cardboard cubic boxes that can be used to build cubic crystals with different morphologies and to do hands-on demonstrations of crystal growth (http:// cristales2014.org/?page_id=1208).

(b) Periodicity, symmetry and order are demonstrated using a $3 \times 3 \times 3 \mathrm{~m}$ model of the $\mathrm{NaCl}$ crystal lattice made of hanging plastic balls. The visitors can walk around the structure looking at the periodic symmetric structure. Under the supervision of teachers, students can even walk inside the crystal', to see crystal planes and crystal directions and to experience symmetry, homogeneity and anisotropy (http:// cristales2014.org/?page_id=1211).

(c) The widespread presence of crystals in our daily life is taught by using an interactive screen that shows the terrace of a restaurant with some people just having fun. When the visitor touches the screen at any point, a pop-up window shows them the crystals present at that point. This application can also be used from the web page (http://cristales2014.org/ ?page_id=1214).

(d) Periodic tessellations, symmetry and periodicity are explained with a set of several thousand plastic tiles that allows the visitor to build all the plane lattices, crystalline, quasicrystalline and amorphous packing, and a large number of symmetric patterns with different symmetry and unit cells. These concepts and a number of suggested hands-on experiments are printed on panels next to each of the three tables making up this installation (http://cristales2014.org/ ?page_id=1218).

(e) Diffraction by periodic objects is demonstrated using a laser diffraction table equipped with two lasers (green and red) and five slides (with two to four patterns each) to test the more relevant concepts involved in diffraction by crystals. The patterns and instructions on how to use them to do hands-on experiments are printed on the table (http://cristales2014.org/ ?page_id=1221).

(f) The importance of crystals and crystallography for health sciences is highlighted by an installation comprising a sculpture of a transparent hexagonal crystal made of plastic, which is filled with pharmaceuticals. The sculpture is on a table and is surrounded by three screens continuously displaying three slide sequences with (1) a presentation on crystallography and the pharmaceutical industry, (2) crystal structures of pharmaceutical compounds, and (3) microscopic views of crystals made of pharmaceutical compounds (http:// cristales2014.org/?page_id=1224).

All these materials and apps are available for teachers and students. In addition, teachers also have access to a specific web page we have created to aid them with some ideas, activities and material on how to use the exhibition in the classroom.

\section{Dissemination and distribution of the exhibition}

The aim of the authors and the producer is to bring the exhibition to the maximum number of schools and universities. Therefore, CRISTALES will be available for download 
at the web site http://cristales.trianatech.com/?page_id=1764 at a resolution high enough for high-quality printing. This will ensure that any educational institution in the world can download the exhibition to freely print and exhibit it, and to use the web site. Two versions are currently available, namely Spanish-English and English-French, and a Spanish-French version will also be produced. Those colleagues and institutions interested in editing the exhibition in other languages, please contact the corresponding author. We plan also to print multiple high-quality copies of the 14 posters of the exhibition that will be mailed within an ad hoc designed poster tube at low cost. Finally, a guidebook of the exhibition has been edited (Cristales: un Mundo por Descubrir/a World to Discover, 2015).

\section{Acknowledgements}

We acknowledge the support of the Fundación Descubre, the Spanish Foundation for Science and Technology (FECYT), and Triana Science and Technology. Special thanks to Martha Santana Ibañez for continuous support and for helping with documentation and legal aspects, and to Teresa Cruz for continuous support. JMGR and FO wrote the texts and selected the scientific content, while CVE, AGC and Josefina Perles (Universidad Autónoma de Madrid) conducted the search for documentation. LAGR is in charge of updating the web content. Production: Triana Science and Technology,
Maquetas Luca de Tena. Design: Todomuta Studio. Printing: Exclama Communication. Webmaster: Andrés GarciaFernandez. Photography: Javier Trueba/Madrid Scientific Films, Hector Garrido, bertys3D/Fotolia, unpict/Fotolia, khunaspix/Fotolia, nanettegrebe/Fotolia. Direction: Juan Manuel García-Ruiz.

\section{References}

Amorós, J. L. (1978). La Gran Aventura del Cristal: Naturaleza y Evolución de la Ciencia de los Cristales, Editorial de la Universidad Complutense, Madrid, Spain.

Cai, Y., Lu, Z. B., Fan, C., Indhumathi, K. T., Lim, C. W., Chan, Y. J. \& Li, L. (2006). Comput. Graph. 30, 3-9.

Cristales: un Mundo por Descubrir/a World to Discover (2015). A Bilingual Guidebook of the Exhibition. Granada: Triana S\&T.

Dalacosta, K. M., Kamariotaki-Paparrigopoulou, J. A. \& Spyrellis, P. N. (2009). Comput. Educ. 52, 741-748.

Dörr, E. (2008). Rudolf Laban: the Dancer of the Crystal. Lanham: Scarecrow Press.

Fanwick, P. E. (2007). Ann. Rep. Comput. Chem. 3, 85-98.

García-Ruiz, J. M. (2015). The Crystal and the Rose. In preparation.

Haüy, R.-J. (1784). Essai d'une Théorie sur la Structure des Crystaux, Appliquée à Plusieurs Genres de Substances Crystallisées, p. 236. Paris: Chez Gogué and Née de la Rochelle.

Knipfer, K., Mayr, E., Zahn, C., Schwan, S. \& Hesse, F. W. (2009). Educ. Res. Rev. 4, 196-209.

Lightman, B. (2013). Endeavour, 37, 82-93.

Moss, K. \& Crowley, M. (2011). Comput. Educ. 56, 36-43.

Sommerauer, P. \& Müller, O. (2014). Comput. Educ. 79, 59-68. 